\title{
Ultrathin Lubricant-Infused Vertical Graphene Nanoscaffolds for High-Performance Dropwise Condensation
}

\section{Journal Article}

Author(s):

Tripathy, Abinash (D); Lam, Cheuk Wing Edmond (D); Dávila, Diana; Donati, Matteo; Milionis, Athanasios; Sharma, Chander Shekhar; Poulikakos, Dimos

Publication date:

2021-09-28

Permanent link:

https://doi.org/10.3929/ethz-b-000501155

Rights / license:

Creative Commons Attribution-NonCommercial-NoDerivatives 4.0 International

Originally published in:

ACS Nano 15(9), https://doi.org/10.1021/acsnano.1c02932

\section{Funding acknowledgement:}

801229 - HierARchical Multiscale Nanolnterfaces for enhanced Condensation processes (EC) 


\title{
Ultrathin Lubricant-Infused Vertical Graphene Nanoscaffolds for High-Performance Dropwise Condensation
}

\author{
Abinash Tripathy," Cheuk Wing Edmond Lam," Diana Davila, Matteo Donati, Athanasios Milionis, \\ Chander Shekhar Sharma, and Dimos Poulikakos*
}

Cite This: ACS Nano 2021, 15, 14305-14315

Read Online

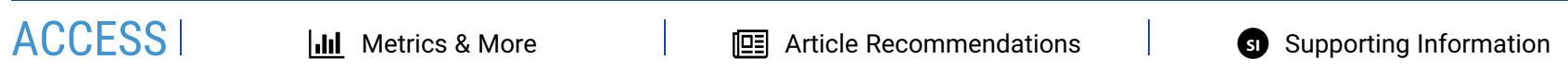

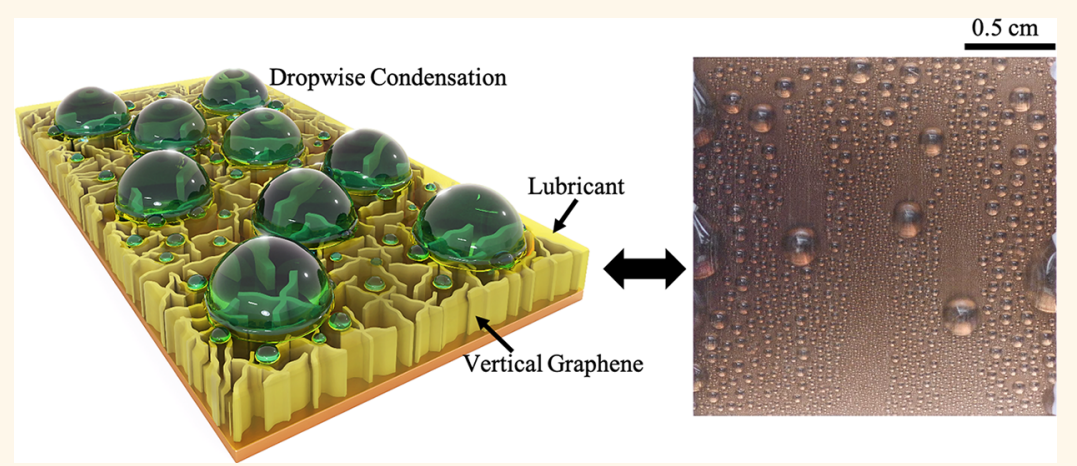

ABSTRACT: Lubricant-infused surfaces (LIS) are highly efficient in repelling water and constitute a very promising family of materials for condensation processes occurring in a broad range of energy applications. However, the performance of LIS in such processes is limited by the inherent thermal resistance imposed by the thickness of the lubricant and supporting surface structure, as well as by the gradual depletion of the lubricant over time. Here, we present an ultrathin $(\sim 70 \mathrm{~nm})$ and conductive LIS architecture, obtained by infusing lubricant into a vertically grown graphene nanoscaffold on copper. The ultrathin nature of the scaffold, combined with the high in-plane thermal conductivity of graphene, drastically minimize earlier limitations, effectively doubling the heat transfer performance compared to a state-of-the-art $\mathrm{CuO}$ LIS surface. We show that the effect of the thermal resistance to the heat transfer performance of a LIS surface, although often overlooked, can be so detrimental that a simple nanostructured $\mathrm{CuO}$ surface can outperform a $\mathrm{CuO}$ LIS surface, despite filmwise condensation on the former. The present vertical graphene LIS is also found to be resistant to lubricant depletion, maintaining stable dropwise condensation for at least $24 \mathrm{~h}$ with no significant change of advancing contact angle and contact angle hysteresis. The lubricant consumed by the vertical graphene LIS is $\mathbf{5 2 . 6 \%}$ less than that of the existing state-of-the-art CuO LIS, also making the fabrication process more economical.

KEYWORDS: dropwise condensation, graphene, nanostructures, heat transfer, slippery surfaces, lubricant, hydrophobicity

\section{INTRODUCTION}

The phenomenon of condensation has many significant applications in technology of daily need, such as thermal management in high-performance computing, power generation, refrigeration, air conditioning, and water desalination. ${ }^{1-4}$ Its manifestation on a surface can be classified into two different modes depending on the condensate temporal accumulation and removal, i.e., filmwise condensation (FWC) and dropwise condensation (DWC) ${ }^{5-7}$ Due to the much higher heat transfer coefficient (HTC) by up to 1 order of magnitude for DWC compared to FWC, attaining and sustaining the dropwise mode is preferred for all applications where efficiency in energy transport is relevant. ${ }^{8-12}$

Recently, employing lubricant-infused surfaces (LIS) in condensation heat transfer has justifiably received increased

Received: April 7, 2021

Accepted: July 23, 2021

Published: August 16, 2021

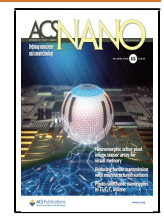




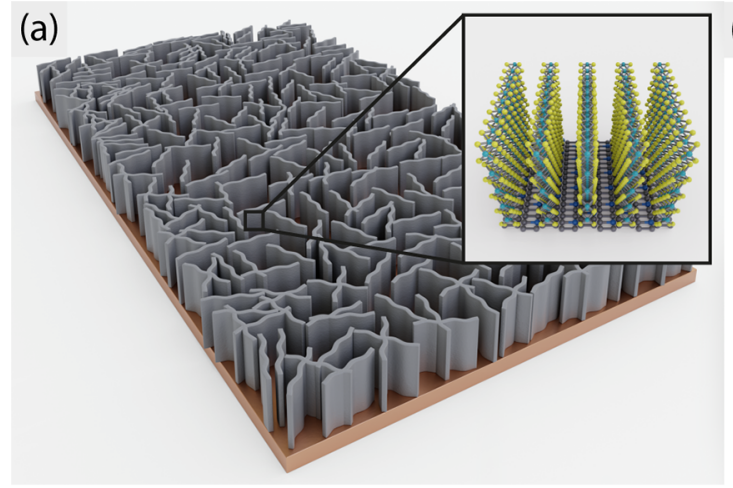

(b)
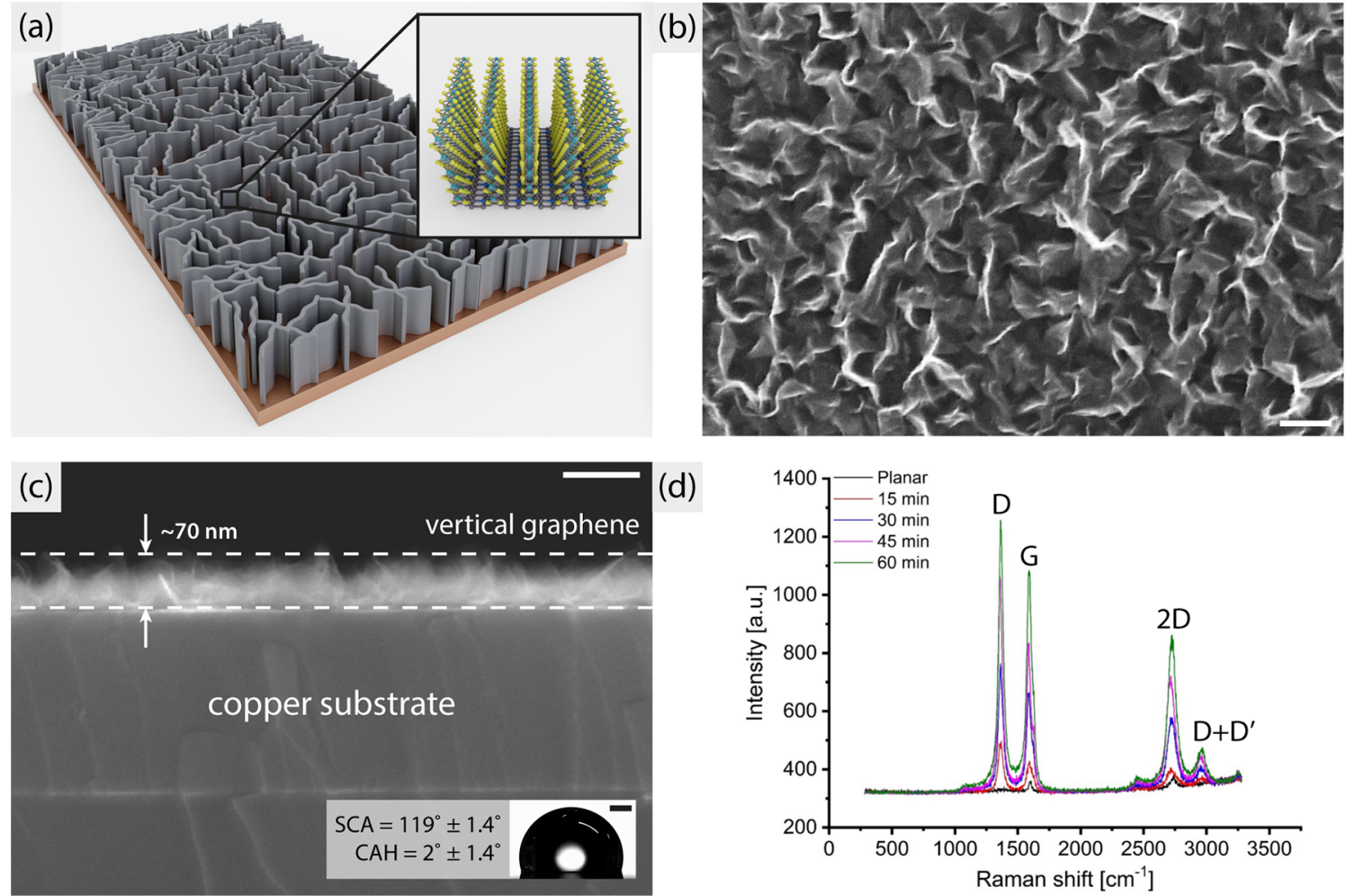

(d)

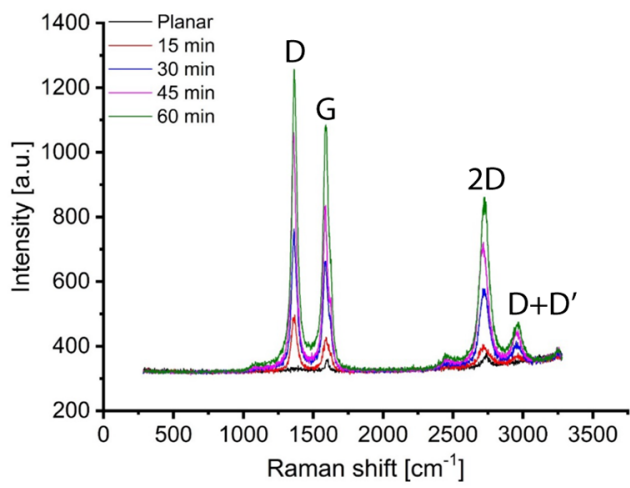

Figure 1. (a) Schematic of VG on copper. CVD was used to grow VG on copper using $\mathrm{CH}_{4}$ gas as the carrier. (b) Top and (c) cross-sectional SEM images of the VG sample grown for $60 \mathrm{~min}$ (scale bar: $100 \mathrm{~nm}$ ). Inset: image of water droplet $(8 \mu \mathrm{L})$ on the VG LIS (scale bar: $0.5 \mathrm{~mm}$ ). (d) Raman spectroscopy of the planar graphene and VG samples with different growth times (15-60 min). G and 2D bands are characteristic to graphitic structures and confirm the presence of graphene. $\mathrm{D}$ and $\mathrm{D}+\mathrm{D}^{\prime}$ bands were observed due to the presence of sharp edges on VG, which were absent for the planar graphene sample.

consideration. Unlike superhydrophobic surfaces, LIS are not prone to flooding of micro- and nanostructures (typical of more common lotus-based superhydrophobic surfaces ${ }^{13-15}$ ) during condensation at high supersaturations. ${ }^{16}$ In the case of superhydrophobic surfaces with hierarchical textures, the extra surface area from the textures allows droplets to nucleate within them and often result in the formation of larger droplets in the Wenzel state on top of such structures, which adhere to the surface and degrade the heat transfer performance, leading to condensate flooding and film formation, ${ }^{17,18}$ although a delay of flooding can be achieved by further surface design for moderate supersaturations. ${ }^{19-21}$ Another alternative approach for obtaining a slippery thin coating for condensation is the use of grafted polymers using initiated chemical deposition (iCVD) techniques. ${ }^{5,22}$ However, the fabrication process is not readily scalable, and the polymer coatings do not have any conductive element in order to reduce the thermal resistance.

In LIS, a lubricant with a low surface energy and a low vapor pressure is typically infused into the micro- and nanostructures present on the surface. ${ }^{23}$ Capillary forces hold the lubricant within the structures and create an extremely smooth and chemically homogeneous surface for condensation. This results in a higher mobility of droplets on LIS, leading to easier continuous removal of condensate and more frequent regeneration of available nucleation sites, both critical to enable and enhance heat transfer by DWC. ${ }^{24-27}$ Typically, the height of the porous structures infused by lubricant in LIS measures a few microns ${ }^{15,24,25,28-30}$ and the amount of lubricant used for creating LIS is proportional to the height of these structures (Table S1). In addition, most LIS have been fabricated on porous materials with low thermal conductivity such as polypyrrole on aluminum, ${ }^{31}$ surface modified and unmodified copper oxide $(\mathrm{CuO}),{ }^{24,25}$ paper $^{32} /$ cellulose $^{33}$ tungsten oxide on steel, ${ }^{34}$ nanoparticles coating, ${ }^{35}$ and porous polymer surfaces. $^{36-39}$ The thermal conductivity of lubricant used in LIS is also low $\left(<0.2 \mathrm{~W} \mathrm{~m}^{-1} \mathrm{~K}^{-1}\right.$ for Krytox oils), which, together with the thickness and the relatively low conductivity of the porous materials employed, translates to an inherent significant thermal resistance of the lubricant layer, thus limiting the potential of using these surfaces for heat transfer applications.

Here, we have carefully designed an alternative LIS scaffold architecture that can alleviate previously mentioned deficiencies of the state-of-the-art. We report an ultrathin $(\sim 70 \mathrm{~nm}) \mathrm{LIS}$, obtained by infusing lubricant into a supporting vertically grown graphene nanoscaffold grown on copper, aiming at significantly promoting DWC and enhancing heat transfer.

Graphene is generally known to have very high in-plane thermal conductivity $\left(2000-4000 \mathrm{~W} \mathrm{~m}^{-1} \mathrm{~K}^{-1}\right),{ }^{40}$ which is attributed to the strong covalent $\mathrm{sp}^{2}$ bonding between the carbon atoms (Figure S1), whereas out-of-plane heat flow is limited by weak interlayer van der Waals coupling. ${ }^{40}$ Between the in-plane and out-of-plane directions, graphene has therefore very high anisotropy in its thermal properties. In addition, graphene exhibits limited wettability close to the hydrophobic regime, ${ }^{41-43}$ and its wetting property can be tuned, for example, by changing the surface roughness. ${ }^{4,45}$ Recently Preston et al. ${ }^{46}$ demonstrated a $4 \times$ enhancement in the HTC for DWC of water on a copper surface coated with graphene along the plane of the surface. This makes graphene a promising material to promote DWC with a higher HTC. 
Vertical graphene (VG), on the contrary, represents a special class of graphitic network, with its plates oriented perpendicularly to a substrate. The rising interest in VG as compared to planar horizontally oriented graphene stems from its vertical orientation itself, its high thermal conductivity in the vertical direction, its porosity and exposed sharp edges, its high surfaceto-volume ratio, and its nonstacking morphology. ${ }^{47-49}$ VG also exhibits hydrophobic behavior, ${ }^{50}$ and the degree of hydrophobicity is higher than that of planar graphene ${ }^{51}$ due to the presence of surface nanoroughness.

The porosity and high surface-to-volume ratio of VG indicate its potential for an enhanced retention of lubricant by capillarity. Hence, we exploit these properties of VG to support infused lubricants and, what is critically important when a minimal thermal resistance is targeted, realize the fabrication of an ultrathin $(\sim 70 \mathrm{~nm})$ VG nanoscaffold, constructing a LIS with outstanding performance with respect to condensation applications. The vertical orientation of graphene brings with it the additional heat transfer benefit related to its extreme thermal conductivity in the vertical direction (Figure 1a). ${ }^{52}$ As an additional benefit, the small thickness of VG LIS minimizes the amount of lubricant required to realize a lubricant-infused texture compared to other LIS.

We have characterized the morphology, chemical composition, and wettability of the above-described VG LIS using scanning electron microscopy (SEM), Raman spectroscopy, and contact angle goniometry, respectively. $\mathrm{CuO} \mathrm{LIS}^{53}$ and a superhydrophilic $\mathrm{CuO}$ nanostructured surface ${ }^{12}$ were chosen as state-of-the-art DWC and FWC reference surfaces, respectively, to compare the performance of VG LIS. Systematic heat transfer measurements at industrially relevant low-pressure saturated steam conditions showed an approximately 2 -fold HTC increase with the VG LIS as compared to $\mathrm{CuO}$ LIS and superhydrophilic $\mathrm{CuO}$ nanostructured surfaces. We also performed prolonged condensation experiments for more than $24 \mathrm{~h}$ to test the durability of the VG LIS as compared to CuO LIS. VG LIS maintained at least twice as high HTC compared to $\mathrm{CuO}$ LIS throughout the durability experiment with minimal change in advancing contact angle and contact angle hysteresis, indicating sustainable droplet mobility on the surface. We have also compared the heat transfer performance of VG LIS with asfabricated VG on copper, planar graphene on copper, $\mathrm{CuO}$ superhydrophobic, and VG superhydrophobic surfaces.

\section{RESULTS/DISCUSSION}

Fabrication of Ultrathin Lubricant-Infused Vertical Graphene Nanoscaffold Surfaces. The growth of VG on copper was carried out using a thermal chemical vapor deposition (CVD) furnace. A catalyst-free approach was employed and $\mathrm{CH}_{4}$ gas was used as the source of carbon. The time of growth of VG was varied between 15 and $60 \mathrm{~min}$. Growth of VG for different time intervals was performed to study the temporal evolution of VG on copper. Growth time of 60 min was found to attribute sufficient uniformity and density to the grown VG nanoscaffold, used to impregnate the lubricant (Figure S2). This growth time was used in all experiments in this work. Before infusing lubricant into the VG nanoscaffold, a $\sim 5$ $\mathrm{nm}$ layer of gold was coated on top, followed by dipping the surface in an ethanolic thiol solution to minimize the surface energy. The gold coating bonds chemically with the thiol. Krytox 1525 was then infused into the nanoscaffold to fabricate the targeted surface (refer to the Methods section for further details). It was found that this process significantly improved the adhesion between the lubricant and the VG nanoscaffold, thus enhancing lubricant retention as we will show later.

Characterization of Lubricant-Infused Vertical Graphene Nanoscaffold Surfaces. In order to realize the minimal thickness of VG network, we selected the minimum VG growth time of $60 \mathrm{~min}$, which resulted in the most uniform surface coverage. The SEM image in Figure $1 \mathrm{~b}$ shows the morphology of VG grown for $60 \mathrm{~min}$, revealing an interconnected VG nanoscaffold network uniformly covering the copper substrate. The height of VG for a growth time of 60 min was found to be $\sim 70 \mathrm{~nm}$ (Figure 1c). The density and thickness of the sidewalls of the VG were also found to increase with the growth time (Figure S2). There was an increase in the sidewall thickness from $\sim 13$ to $\sim 32 \mathrm{~nm}$ when the growth time was increased from 15 to $60 \mathrm{~min}$ (Table S2).

Raman spectroscopy is a powerful, nondestructive, and fast technique to study the properties of graphene. This technique provides information regarding the orientation and number of layers, the presence of defects and edges, etc. ${ }^{52,54,55}$ Figure $1 \mathrm{~d}$ shows the Raman spectra of the planar and VG samples used in our study. We observed the G peak $\left(\sim 1594 \mathrm{~cm}^{-1}\right)$ and the 2D peak $\left(\sim 2727 \mathrm{~cm}^{-1}\right)$ for all the samples. These bands are characteristic to graphitic structures and confirm the presence of graphene sheets. ${ }^{56-58}$ In addition to that, we observed the D $\left(\sim 1365 \mathrm{~cm}^{-1}\right)$ and $\mathrm{D}+\mathrm{D}^{\prime}\left(\sim 2972 \mathrm{~cm}^{-1}\right)$ peaks for the substrates with VG. ${ }^{59}$ In planar graphene, these bands $\left(\mathrm{D}\right.$ and $\left.\mathrm{D}+\mathrm{D}^{\prime}\right)$ are absent. The presence of high-intensity $\mathrm{D}$ and $\mathrm{D}+\mathrm{D}^{\prime}$ peaks signify a larger number of sharp edges in our VG samples. ${ }^{60}$

The surface wetting property of VG was determined before and after the impregnation of lubricant. Using the sessile drop method, the contact angle measurement was performed with deionized water droplets. Before lubricant impregnation, the advancing contact angle (ACA) of VG was $123^{\circ} \pm 2.2^{\circ}$ (Table S2 and Figure S3) with a contact angle hysteresis (CAH) of $66^{\circ}$ $\pm 2.7^{\circ}$, indicating high water adhesion, which inhibits droplet movement. After lubricant impregnation (Figure S4), the ACA was $119^{\circ} \pm 1.4^{\circ}$ and the $\mathrm{CAH}$ was $2^{\circ} \pm 1.4^{\circ}$. The massive decrease in $\mathrm{CAH}$ and the corresponding increased mobility of water droplets is critical for enhancing heat transfer through the frequent removal of droplets.

Contact angle measurements were performed for the other two reference surfaces as well. The static contact angle (SCA) value for an as-fabricated uncoated $\mathrm{CuO}$ nanostructured surface (Figure S5) was $\sim 0^{\circ}$, and the ACA and CAH values for $\mathrm{CuO}$ LIS ( $\mathrm{CuO}$ nanostructured surface coated with thiol and infused with lubricant) were $119.7^{\circ} \pm 1.2^{\circ}$ and $3.7^{\circ} \pm 1.8^{\circ}$, respectively. A $\mathrm{CuO}$ nanostructured surface was used as the reference for stable FWC, ${ }^{12}$ and $\mathrm{CuO}$ LIS was used to compare our surface with the existing state-of-the-art for DWC on lubricant-infused surfaces. $^{25,53}$

To measure the amount of lubricant required to fabricate VG LIS and CuO LIS, the samples were weighed before and after infusing the lubricant. VG LIS $\left(9 \mathrm{~g} \mathrm{~m}^{-2}\right)$ consumed $52.6 \%$ less lubricant than $\mathrm{CuO}$ LIS $\left(19 \mathrm{~g} \mathrm{~m}^{-2}\right)$. This is due to the smaller height of VG ( $\sim 70 \mathrm{~nm})$ as compared to $\mathrm{CuO}$ nanostructures $(\sim 2 \mu \mathrm{m})$ and the larger spacing between the $\mathrm{CuO}$ nanostructures, which ranged from 0.3 to $0.7 \mu \mathrm{m}$, whereas the spacing between the sidewalls in the VG nanoscaffold was 30$90 \mathrm{~nm}$. The smaller length scale of the vertical graphene nanoscaffold surface structures as compared to the $\mathrm{CuO}$ nanostructures indicates that the former will exhibit a stronger capillary force to retain the lubricant. 
(a)

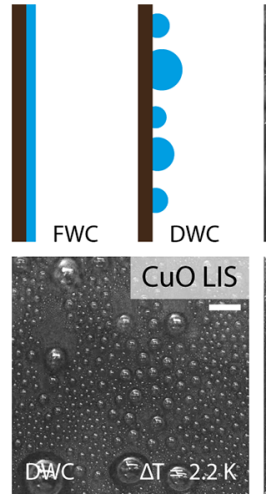

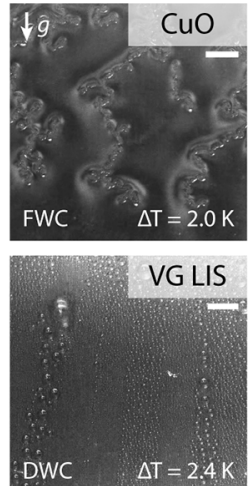

(b)

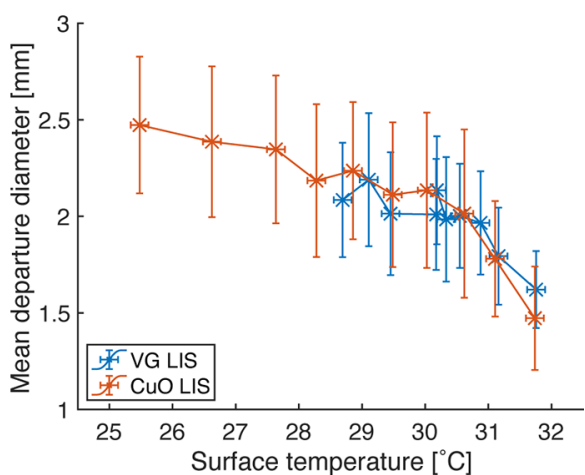

Figure 2. (a) Condensation modes on the $\mathrm{CuO}$ nanostructured surface, $\mathrm{CuO}$ LIS, and VG LIS at $\sim 2 \mathrm{~K}$ subcooling. Schematic shows a side view of the two condensation modes. A continuous film of water on the $\mathrm{CuO}$ nanostructured surface presents as a significant additional thermal resistance on top of the surface compared to periodically shedding condensate droplets for CuO LIS and VG LIS surfaces (scale bar: 2 mm). (b) Mean departure diameter on the two surfaces as a function of surface temperature $T_{\text {surf }}$ Steam temperature was kept constant at $\sim 32.9^{\circ} \mathrm{C}$. The trend of decreasing diameters with increasing surface temperatures was observed on both surfaces. Vertical error bars indicate the standard deviation of the departure diameter distribution. Horizontal error bars indicate uncertainty in the surface temperature measurements.

The capillary length $\left(\kappa^{-1}\right)$ of Krytox 1525 used in our study was $\sim 1.01 \mathrm{~mm}\left(\sqrt{\frac{\gamma}{\rho g}}, \gamma=19 \mathrm{mN} \mathrm{m}^{-1}, \rho=1900 \mathrm{~kg} \mathrm{~m}^{-3}, g=9.8 \mathrm{~m}\right.$ $\left.\mathrm{s}^{-2}\right){ }^{61}$ The length scale of VG nanostructures is much smaller than the $\kappa^{-1}$ of Krytox 1525, which suggests its ability to enhance lubricant retention, benefiting from capillarity. ${ }^{62}$ To study the lubricant retention ability of VG LIS further, we subjected the substrate to high-shear conditions by spinning it at $5000 \mathrm{rpm}$ (Figure S6). In our experiment, the centrifugal force is the source of the high-shear condition. At this rotational speed, the acceleration in terms of $\mathrm{g}$-force at a distance of $2 \mathrm{~cm}$ from the center of the substrate is $r \omega^{2}=0.02 \times(5000 \times 2 \pi / 60)^{2} \approx 560 g$, the location at which we measured the $\mathrm{CAH}$ on the substrates directly after the spinning test. The capillary length, $\kappa^{-1}$, of Krytox 1525 at $560 \mathrm{~g}$ becomes $42.69 \mu \mathrm{m}\left(\kappa^{-1}\right.$ is $21.34 \mu \mathrm{m}$ at $10000 \mathrm{rpm}$ ). This value was still 3 orders of magnitude larger than the structures present on VG LIS, indicating that the surface should be able to retain the lubricant under such rapid spinning conditions. The measured CAH values on VG LIS were $2^{\circ} \pm 1.4^{\circ}$ and $2.3^{\circ} \pm 1.2^{\circ}$ before and after the spinning test, respectively, verifying this claim. The unchanged CAH after the spinning test indicated that VG LIS has superb lubricant retention ability under high-shear conditions, an important experimental design parameter to be considered while fabricating lubricant-infused surfaces, as the durability of the surface depends heavily on lubricant retention.

In addition to the above test, we also performed a water sliding test on the VG LIS to investigate the lubricant depletion due to sliding droplets. The surface was kept at angle of $60^{\circ}$, and millimeter-sized deionized water droplets were allowed to slide on the surface continuously (Figure S7). We collected the water falling from the surface. This test was carried out for $7 \mathrm{~h}$. We measured the advancing contact angle (ACA) and contact angle hysteresis $(\mathrm{CAH})$ at every $1 \mathrm{~h}$ at the sliding traces of the deionized water droplets. Table S3 provides the ACA and CAH values over the course of the experiment. We did not observe any significant change in the ACA and $\mathrm{CAH}$ values after the water sliding test. In addition, lubricant was not observed in the collected water after the experiment. This might be because of the higher viscosity of Krytox 1525 (261 cSt at $\left.20{ }^{\circ} \mathrm{C}\right)$, which delayed cloaking events, ${ }^{63}$ and the water droplet left the surface before the lubricant could engulf it.
Heat Transfer Coefficient Measurements. In order to characterize the effect of reduced thermal resistance of VG LIS, we performed careful measurements of its heat transfer performance under industrially relevant operating conditions. We directly measured the condensation heat flux and heat transfer coefficient and compared these to standard FWC heat transfer as well as DWC on state-of-the-art LIS. As discussed earlier, for FWC, a $\mathrm{CuO}$ nanostructured surface was used as a baseline reference. For DWC performance comparison, $\mathrm{CuO}$ LIS was used.

The surfaces were placed vertically in a custom-built flow condensation chamber and were exposed to $50 \mathrm{mbar}$ pure saturated steam flowing horizontally and tangentially over the surface at $\sim 3.7 \mathrm{~m} / \mathrm{s}$, while varying the sample temperature. Refer to Sections S1 and S2 for details in experimental procedures and measurement, Section S3 for chamber leakage estimation, and Section S4 for steam flow speed estimation. Section S5 includes the thermal resistance estimation of the lubricant or nanostructure layer.

Figure 2a shows visually the condensation behavior on the three surfaces at a subcooling value $\Delta T$ around $2 \mathrm{~K}$. Videos of the condensation behavior on the three surfaces can be found in Movie S1. DWC manifested itself on the lubricant-infused surfaces of VG LIS and CuO LIS, whereas the condensation was filmwise on the superhydrophilic $\mathrm{CuO}$ nanostructured surface. We measured departure diameters for all droplet departure events in a 1 min period at different subcooling values. The mean measured diameters are presented in Figure $2 b$ as a function of the surface temperature, $T_{\text {surf }}$ Error estimation can be found in Section S6. Droplet measurement procedures can be found in Section S7. The minimum attainable surface temperature was limited by the performance of the surface, i.e., a more efficient surface renders a smaller range of attainable surface temperatures, thus a smaller range of subcooling values, as there is less resistance for the surface to approach the fixed steam temperature. The two surfaces exhibited similar diameters and the same general trend of decreasing diameters with increasing surface temperatures, which we attribute to the increase of nucleation rate at lower surface temperatures, given a constant steam temperature of $\sim 32.9{ }^{\circ} \mathrm{C}$. The departure droplet diameters span mainly between 1.5 and $2.5 \mathrm{~mm}$, slightly below the capillary length of $2.7 \mathrm{~mm}$ for water. The full distribution of the measurements can be found in Figure S8. The results suggest 
(a)

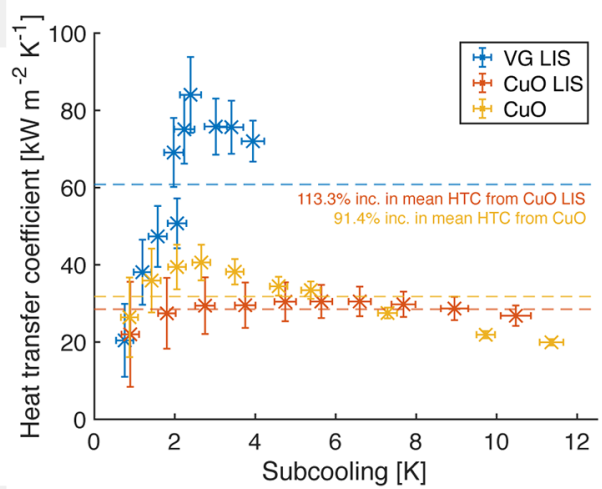

(c)

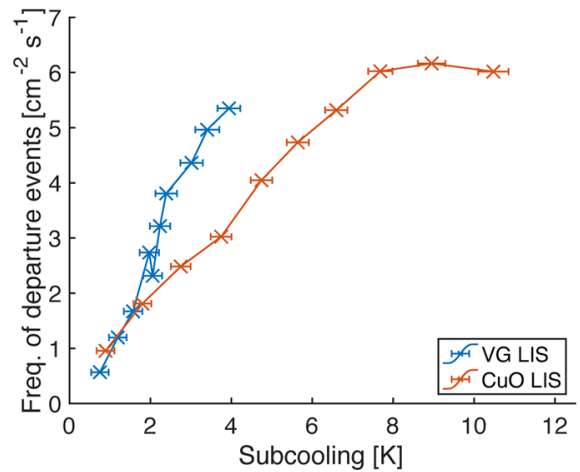

(b)

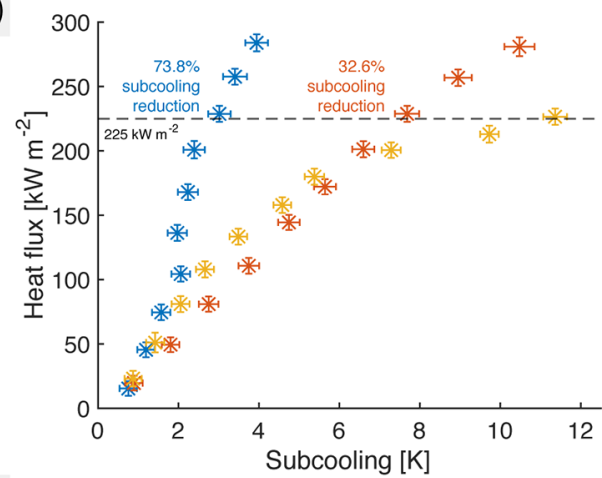

(d)

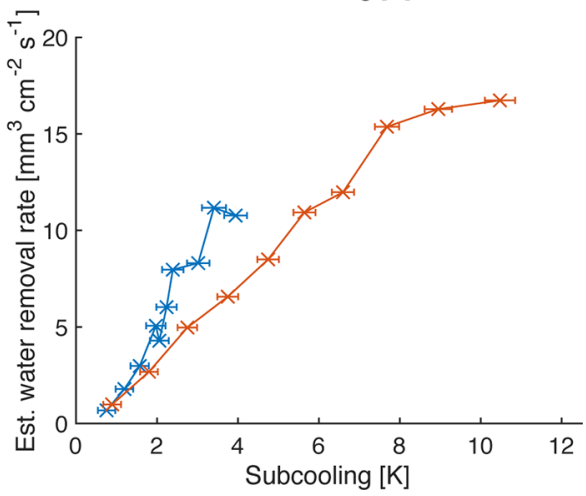

Figure 3. (a) HTC of VG LIS, CuO LIS, and the CuO nanostructured surface at different subcooling values $\Delta T=T_{\text {steam }}-T_{\text {base }}$. The range of the attained subcooling values is influenced by the performance of the interface. A better performing surface shifts the maximum attainable subcooling value to the left (smaller subcooling values). On average across these 10 data points (arithmetic mean, indicated by dashed lines), VG LIS presented a 113.3\% increase from $\mathrm{CuO}$ LIS and a $91.4 \%$ increase from the $\mathrm{CuO}$ nanostructured surface. (b) Corresponding heat flux measurements. At the same subcooling values, VG LIS can maintain the highest heat flux among the three surfaces. (c) Rate of droplet departure measured on VG LIS and CuO LIS in an area of $10 \mathrm{~mm} \times 10 \mathrm{~mm}$ around the center of the sample. At $2 \mathrm{~K}$ subcooling and beyond, droplet departure was more frequent on VG LIS than CuO LIS. (d) Estimated water removal rate from the two surfaces on the basis of measured individual droplet departure diameters. With similar mean departure diameters in Figure $2 b$ and the deviation of droplet departure frequency of the two surfaces after $2 \mathrm{~K}$ subcooling (panel c), the water removal rate after $2 \mathrm{~K}$ on VG LIS deviated from CuO LIS as well.

that the surface properties are similar during condensation for both surfaces, being dominated by the lubricant.

We then investigated the condensation behavior on the three surfaces as a function of the subcooling, defined as $\Delta T=T_{\text {steam }}$ $T_{\text {base, }}$, where $T_{\text {steam }}$ is the steam temperature $\left(\sim 32.9^{\circ} \mathrm{C}\right)$ and $T_{\text {base }}$ is the temperature below the lubricant or nanostructure layer computed from the Fourier's law of thermal conduction (Section S5).

The HTC was computed from the measured sample temperature and heat flux into the cooled surface. We defined the HTC as $h=q^{\prime \prime} / \Delta T$, where $q^{\prime \prime}$ is the measured heat flux. The use of $\Delta T=T_{\text {steam }}-T_{\text {base }}$ computed from the base temperature below the lubricant or nanostructure layer incorporated its thermal resistance into the HTC definition by construction. In Figure 3a, we report the HTC measurements for each surface at 10 different subcooling values, obtained by setting the heat sink at 10 different temperatures for a constant saturated steam temperature at 50 mbar. As a better performing surface introduces less interfacial heat transfer resistance, the subcooling values it yields will naturally drift to the lower values, at the same time resulting in higher HTCs. Computing the arithmetic mean across all values investigated, $\mathrm{CuO}$ LIS performed similarly to the superhydrophilic $\mathrm{CuO}$ nanostructured surface. In contrast, VG LIS performed $91.4 \%$ better on average compared to the $\mathrm{CuO}$ nanostructured surface and $113.3 \%$ better compared to $\mathrm{CuO}$ LIS. At a subcooling of $2.4 \mathrm{~K}$ where VG LIS performed the best, the improvement over the $\mathrm{CuO}$ nanostructured surface was
$109.2 \%$ and that over CuO LIS was $192.4 \%$. The benefit of DWC on $\mathrm{CuO}$ LIS was diminished by the thermal resistance accompanied by its relatively thick lubricant layer.

The corresponding heat flux measurements are shown in Figure $3 \mathrm{~b}$. At a heat flux of $225 \mathrm{~kW} \mathrm{~m}^{-2}$, VG LIS could sustain the condensation at $73.8 \%$ smaller subcooling than the $\mathrm{CuO}$ nanostructured surface, compared to a $32.6 \%$ smaller subcooling of $\mathrm{CuO}$ LIS. At $3.8 \mathrm{~K}$ subcooling, the heat flux yielded by VG LIS was $97.4 \%$ higher than that of the $\mathrm{CuO}$ nanostructured surface and $146.3 \%$ higher than that of $\mathrm{CuO}$ LIS.

These results indicate that, considering the thermal resistance of the lubricant layer, which is inherent in all LIS, the improvement of HTC for DWC on CuO LIS was effectively lost. If this resistance was left out from the computation of the HTC, CuO LIS would show an artificial improvement over reference $\mathrm{FWC}$ on the $\mathrm{CuO}$ nanostructured surface. The apparent restoration, however, is solely a result of neglecting to account for the lubricant layer thermal resistance. For completeness, Section S8 describes the measured HTCs when the thermal resistance is not taken into account.

We emphasize here the significant and detrimental impact on the heat transfer efficiency of using low-adhesion layers to achieve DWC, which is often neglected in coating design. In attempts to achieve DWC with LIS, these layers simultaneously add thermal resistance due to the low thermal conductivity of the porous matrix as well of the lubricant, which are typically both poor thermal conductors. For lubricants, the thermal 
(a)

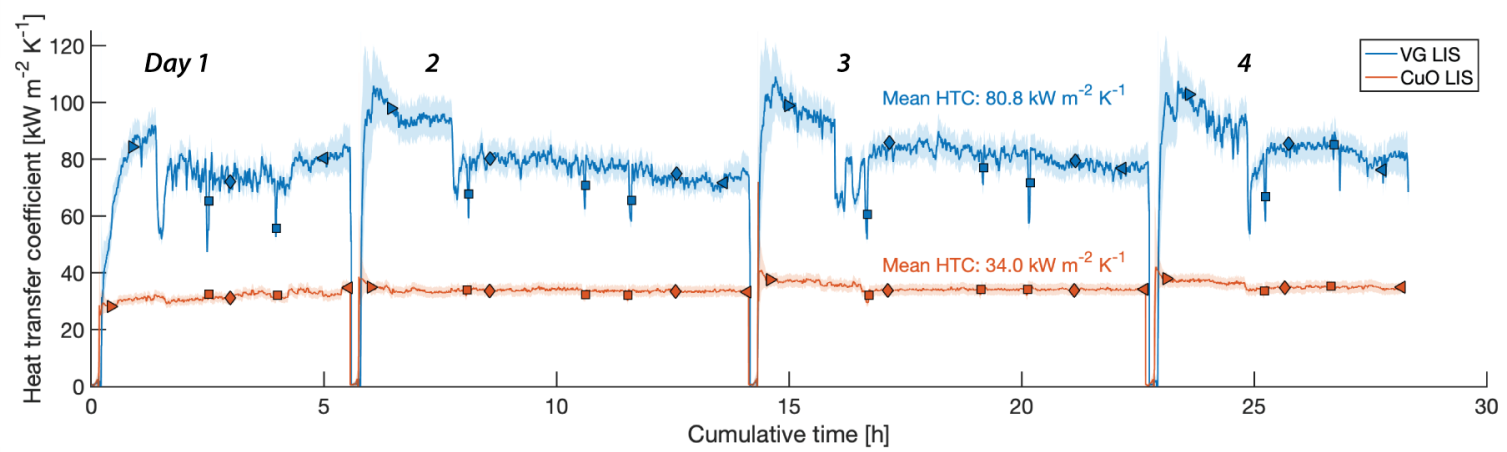

(b)

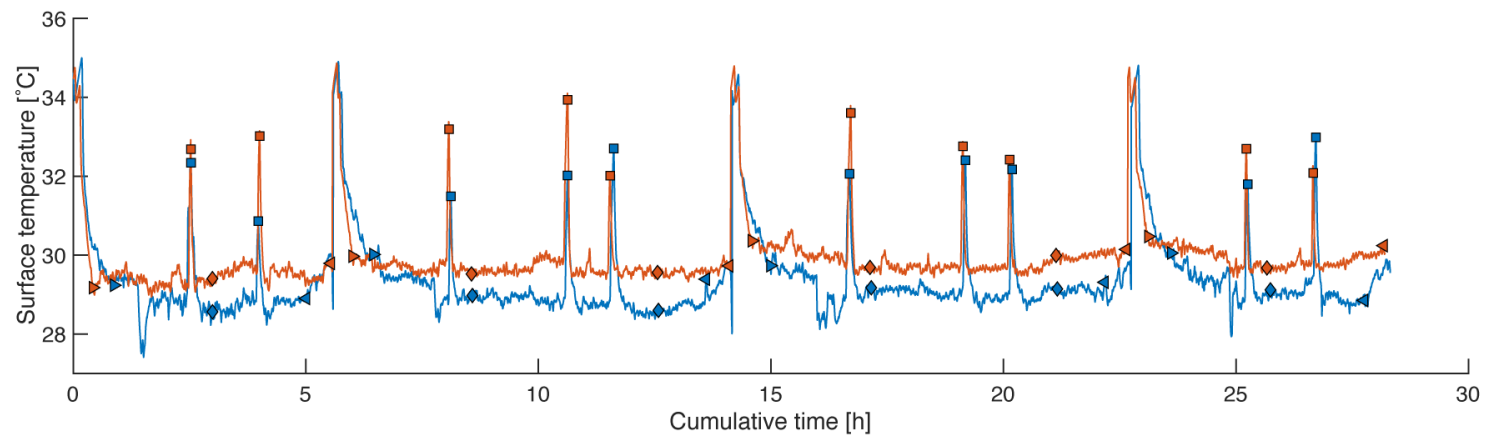

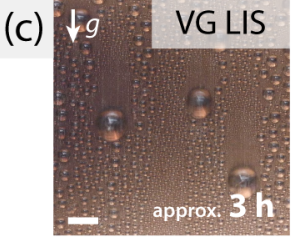

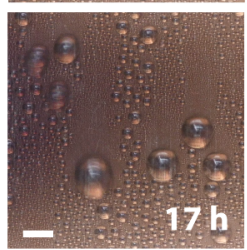

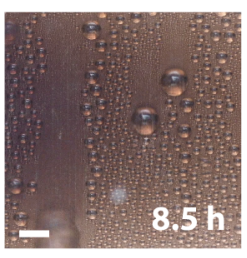

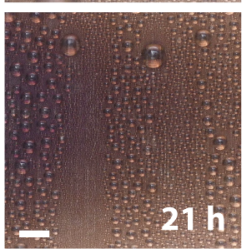

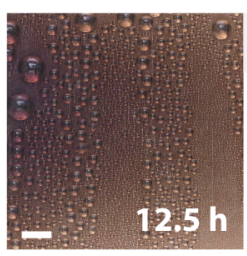

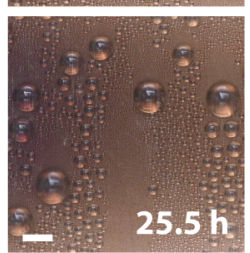

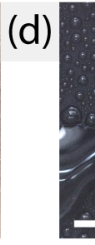
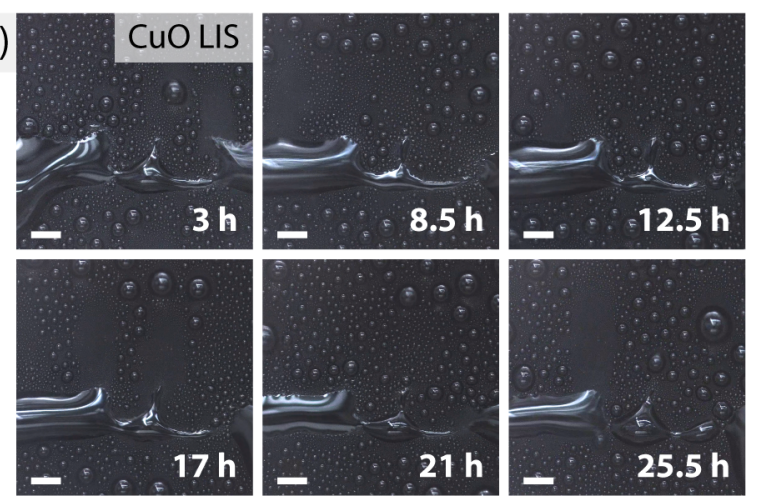

Figure 4. (a) HTC measurement on VG LIS and CuO LIS for more than $24 \mathrm{~h}$, as $1 \mathrm{~min}$ moving average. The data curve begins for each day when steam was introduced into the evacuated chamber. Rightward and leftward triangles refer to the time points when the heat sink reached and left the target temperature, respectively. Squares denote when the flow was reduced temporarily for setup maintenance. Diamonds refer to the exact time points of snapshots shown in panels $\mathrm{c}$ and $\mathrm{d}$. Mean HTC values were computed for the period when the heat sink was steady at the target temperature. (b) Corresponding surface temperature evolution during the period as $1 \mathrm{~min}$ moving average. Appearance of condensate droplets on (c) VG LIS and (d) $\mathrm{CuO}$ LIS during the experiment. A pinning site is seen on $\mathrm{CuO}$ LIS. Time points on the snapshots are approximate cumulative times (scale bar: $2 \mathrm{~mm}$ ).

conductivity is typically on the order of $0.1 \mathrm{~W} \mathrm{~m}^{-1} \mathrm{~K}^{-1}, 3$ orders of magnitude lower compared to metals with thermal conductivities on the order of $100 \mathrm{~W} \mathrm{~m}^{-1} \mathrm{~K}^{-1}$. The porous matrix in typical LIS is composed of metal oxides, which also have thermal conductivities far below those of metals, e.g., $\mathrm{CuO}^{64}$ has a thermal conductivity of $33 \mathrm{~W} \mathrm{~m}^{-1} \mathrm{~K}^{-1}$. Therefore, to truly harness the benefits of DWC, a low-adhesion lubricantinfused texture with simultaneous minimal thermal resistance is required, and consequently, the effect of thermal resistance must be taken into account to correctly determine the heat transfer effectiveness of the lubricant-infused texture.

Our approach circumvents this inherent and prohibitive drawback of LIS from two very effective directions: By significantly reducing the thickness of the lubricant-infused texture and by increasing the thermal conductivity of the solid porous matrix using a vertically oriented graphene nanoscaffold. Using the thermal conductivities of the lubricant Krytox 1525 $\left(0.1 \mathrm{~W} \mathrm{~m}^{-1} \mathrm{~K}^{-1}\right)$, vertical graphene ${ }^{52}\left(250 \mathrm{~W} \mathrm{~m}^{-1} \mathrm{~K}^{-1}\right)$, and
$\mathrm{CuO}^{64}\left(33 \mathrm{~W} \mathrm{~m}^{-1} \mathrm{~K}^{-1}\right)$, as well as the heights of the structures, we computed the thermal resistance of the lubricant-infused nanotextures to be $0.0011 \mathrm{~K} \mathrm{~W}^{-1}$ for VG LIS and $0.0317 \mathrm{~K} \mathrm{~W}^{-1}$ for $\mathrm{CuO}$ LIS for a $20 \mathrm{~mm} \times 20 \mathrm{~mm}$ surface, the area exposed to steam in our condensation experiments. At a heat flux of $225 \mathrm{~kW}$ $\mathrm{m}^{-2}$ in our experiments, for example, this would translate to a temperature difference of $\sim 0.1 \mathrm{~K}$ across the lubricant layer for VG LIS but $\sim 2.9 \mathrm{~K}$ for $\mathrm{CuO}$ LIS. Normalized to a condensing surface area of $1 \mathrm{~m}^{2}$, the thermal resistance values would be 4.53 $\times 10^{-7}$ and $1.27 \times 10^{-5} \mathrm{~K} \mathrm{~W}^{-1}$ for VG LIS and $\mathrm{CuO}$ LIS, respectively. In other words, we achieved, by design, an order-ofmagnitude reduction in the thermal resistance of the lubricant layer in VG LIS compared to that of state-of-the-art CuO LIS, which directly contributes to the difference in the heat transfer performance illustrated in Figure 3a,b. Refer to Section S5 for details on the estimation of thermal resistance of the considered LIS. 
The number of departure events shown in Figure $3 \mathrm{c}$ supports the HTC measurements. We chose a window of $10 \mathrm{~mm} \times 10$ $\mathrm{mm}$ around the center of the sample for measuring droplet departure (Section S7) to avoid edge effects. With similar mean departure diameters in Figure $2 b$, a higher number of departure events at the same subcooling value suggests more water condensed and thus a higher condensation heat transfer efficiency. The droplet departure event curves for VG LIS and $\mathrm{CuO}$ LIS diverge markedly beyond $2 \mathrm{~K}$ subcooling, consistent with HTC and heat flux curves in Figure 3a,b. Similarly, we estimated the water removal rate of the two samples by using the individually measured departure diameters, assuming a spherical cap droplet shape, calculated on the basis of the static contact angle for the departing water droplets in Figure $3 \mathrm{~d}$. This is a rough estimation since $\mathrm{CAH}$ and the coalescence events of the departing droplets immediately before measurement may distort their shape from a perfect spherical cap geometry. Nevertheless, a clear deviation beyond $2 \mathrm{~K}$ was still observed. The heat transfer performance of VG LIS was also compared with those of asfabricated VG on copper, planar graphene on copper, $\mathrm{CuO}$ superhydrophobic, and VG superhydrophobic surfaces (Section S9).

In addition to the heat transfer performance of a LIS, it is also important to verify whether the texture can retain the lubricant successfully under condensation conditions over time, where the shear from sliding droplets and steam flow can cause a gradual drainage and loss of lubricant and consequent degradation in surface heat transfer performance. We demonstrate in the following section that VG LIS can sustain its performance for long periods of time under industrially relevant conditions.

Durability Experiment. To test the durability performance of the VG LIS surface, we exposed it to the same conditions as in the HTC measurement experiments, i.e., saturated steam at 50 mbar, for more than $24 \mathrm{~h}$. To our knowledge, studies of this type, i.e., prolonged condensation of water on lubricated surfaces, to allow for comparison have not been performed in the literature (in the work of Preston et al., ${ }^{53}$ the durability of CuO LIS was shown by continuously condensing toluene on the surface), despite the clear need to address the performance of LIS over time.

The performances of VG LIS and CuO LIS are reported in Figure 4. The experiment was split into four consecutive days, during which we exposed the surfaces to steam at a $\sim 5.5-8.5-$ 8.5-5.5 h per day sequence. For each day, the beginning of the data curve is the time when steam was introduced into the evacuated chamber. The heat sink temperature was set when the chamber pressure reached the target pressure of $50 \mathrm{mbar}$. As the heat sink temperature dropped, condensation soon followed as the surface temperature quickly dropped below the steam temperature (Section S4). We compared VG LIS and CuO LIS at a similar surface temperature $T_{\text {surf }}$ which, at the same steam temperature, resulted in a similar nucleation rate and thus similar shear dynamics on the lubricant. We targeted a surface temperature $T_{\text {surf }} \approx 29{ }^{\circ} \mathrm{C}$ at the beginning of the durability experiment, and the corresponding target heat sink temperature was fixed for the rest of the days. The time when the heat sink reached the target temperature is indicated by rightward triangles in Figure 4a,b. For VG LIS, a lower heat sink temperature was necessary to maintain the same surface temperature as $\mathrm{CuO}$ LIS, thus it took more time to reach the target temperature. In the durability experiment, there were occasions when steam flow had to be reduced temporarily for a few minutes for maintenance of our setup, as indicated by squares. These resulted in a temporary perturbation in measured parameters, but all returned to nominal or original values after the short maintenance period. At the end of the duration for the day, indicated by leftward triangles, the heat sink was set to revert to higher temperatures so that the experiment of the day could be stopped. The period between the triangles thus indicates a steady heat sink temperature, for which we computed the mean HTC for the surfaces. VG LIS maintained a significantly higher HTC (137.6\% improvement in the temporal mean) than the $\mathrm{CuO}$ LIS reference, as shown in Figure 4a. Moreover, after each day of experiment, we noticed a recovery of HTC for VG LIS, which was repeatedly seen on the following day. We suspect a restabilization of the surface when it was not condensing.

Snapshots of both surfaces at different times are shown in Figure $4 c, d$. These times are indicated as diamonds in Figure $4 \mathrm{a}, \mathrm{b}$, which are at approximately 3 and $7 \mathrm{~h}$ (for $8.5 \mathrm{~h}$ experiments) into the experiment of the day. A pinning site was seen early on the first day of test on $\mathrm{CuO}$ LIS and maintained for the rest of the experiment. After the durability experiment, $\mathrm{CAH}$ was measured on both surfaces, and the increase as compared to prior the test was markedly more prominent on $\mathrm{CuO}$ LIS $\left(+81.3^{\circ}\right)$ than VG LIS $\left(+4^{\circ}\right)$. A movie of the condensation on VG LIS at different time points can be found in Movie S2.

\section{CONCLUSION}

We have introduced and investigated a lubricant-infused surface architecture based on VG nanoscaffolds grown on copper, which can exhibit the stable DWC of water for at least $24 \mathrm{~h}$, meanwhile achieving significant heat transfer improvement over the stateof-the-art $\mathrm{CuO}$ LIS. The key advance in the material design comes from the vertical, highly conductive, and ultrathin graphene nanostructures that are able to support a proportionally thin lubricant layer $(\sim 70 \mathrm{~nm})$, with the layer thinness being a critical advancement over the state-of-the-art regarding heat transfer performance. This minimizes the inherent thermal resistance of this composite coating (order-of-magnitude reduction compared to the reference state-of-the-art $\mathrm{CuO}$ LIS), while exhibiting excellent lubricant retention while consuming only half of the lubricant as compared to $\mathrm{CuO}$ LIS and yielding a 2 -fold heat transfer efficiency. This work brings to the forefront the critical need to design LIS surfaces for heat transfer condensation applications with minimal thermal resistance and always rate them without neglecting their thermal resistance. The simple and scalable fabrication of the VG LIS coating reported here significantly advances the state-of-the-art and offers itself as a promising candidate for a host of condensation applications.

\section{METHODS}

Growth of Vertical Graphene (VG). Vertical graphene was grown using a catalyst-free method in a thermal CVD furnace (TCVD RF100CA 2G growth tool, Graphene Square Inc.) with a tubular design configuration and equipped with an inductively coupled plasma (ICP) unit. The substrates (copper pieces acquired from Metall Service Menziken and Lasercut AG, $1.5 \mathrm{~mm}$ thick, $5 \mathrm{~cm} \times 2 \mathrm{~cm}$ ) were cleaned in subsequent baths of acetone, isopropanol, and DI water. $\mathrm{O}_{2}$ plasma was then used to eliminate any possible organic contaminants on the sample. This step oxidized the surface of the copper, which was further etched for $1 \mathrm{~min}$ in a mixture of $\mathrm{HCl} / \mathrm{H}_{2} \mathrm{O}(1: 10)$ prior to growth.

The samples were then immediately introduced in the CVD furnace at room temperature and heated to $750{ }^{\circ} \mathrm{C}$ under a $20 \mathrm{sccm} \mathrm{H}_{2}$ flow. Once this temperature was reached, the samples were allowed to 
stabilize for 10 min under the same $\mathrm{H}_{2}$ flow. At this point, methane $\left(\mathrm{CH}_{4}\right)$ was introduced as the carbon source for the vertical growth of vertical graphene nanosheets. $\mathrm{A} \mathrm{H}_{2} / \mathrm{CH}_{4}$ flow ratio of 6:9, an $\mathrm{RF}$ power of $200 \mathrm{~W}$, and a pressure of 0.045 Torr were used. The growth time was varied from 15 to $60 \mathrm{~min}$ to achieve different layer thicknesses. Following the growth of the vertical graphene, the substrates were allowed to cool down under a $20 \mathrm{sccm} \mathrm{H}_{2}$ flow until room temperature was reached. The samples were then removed from the furnace. No post-transfer procedure was needed afterward as the vertical graphene grew directly on the surface of the copper samples. Only for at least 60 min of growth time was the growth of VG structures uniform all across the surface and dense. Hence, nanoscaffold VG samples grown for 60 min were used in all our experiments and the growth time was not increased further. The growth of VG structures on surfaces other than copper can be performed with an additional thin layer of copper (100$150 \mathrm{~nm}^{65}$ ) deposited on top of the surface of interest, making the above fabrication process versatile for a broad range of materials. During the fabrication of vertical graphene, first, the gas molecules $\left(\mathrm{CH}_{4}, \mathrm{H}_{2}\right)$ in the CVD chamber are dissociated by the RF plasma. The carbon radicals then arrive on top of the copper substrate and a base graphite layer is formed parallel to the substrate. In this base layer due to internal stress, many cracks are found. ${ }^{66}$ The density of these cracks increases and the edges of these cracks curl in the upward direction due to continuous decomposition and deposition of the carbon radicals. The presence of electric field induced by the RF plasma perpendicular to the copper substrate allows the carbon atoms to bond to the edge of the cracks and graphene nanosheets start to grow vertically.

Pristine graphene was grown by heating the furnace to $930{ }^{\circ} \mathrm{C}$ under a $5 \mathrm{sccm} \mathrm{H}_{2}$ flow and then introducing a $40 \mathrm{sccm} \mathrm{CH}_{4}$ flow for a period of $35 \mathrm{~min}$ at a pressure of 0.170 Torr. The samples were then cooled under a $5 \mathrm{sccm} \mathrm{H}_{2}$ flow.

Surface Characterization of VG. The morphological structure of the vertical graphene was analyzed using a scanning electron transmission microscope (SU8230, Hitachi). A Raman spectroscopy setup (NT-MDT NTEGRA Spectra) was employed to verify the chemical composition of the samples. Raman measurements were carried out using a $50 \mathrm{~mW}$ solid-state laser with an excitation wavelength of $473.05 \mathrm{~nm}$ in single longitudinal mode and linearly polarized. The light was collected using a $100 \times$ long-working distance objective (working distance of $7 \mathrm{~mm}$ and numerical aperture of 0.7 ) and detected by a Peltier-cooled ultralow noise charge-coupled device (CCD) camera. A 600 lines per $\mathrm{mm}$ grating was used to measure the complete Raman spectra at localized areas with an acquisition time of $10 \mathrm{~s}$.

Fabrication of Lubricant-Infused VG. To prepare the lubricantinfused VG samples, first, the samples were coated with $5 \mathrm{~nm}$ of gold using e-beam evaporation (BAK 501LL, Evatech). For practical applications, this can be replaced with an ultrathin layer of either copper or aluminum. The gold coated VG samples were dipped into an ethanolic thiol solution for $1 \mathrm{~h}^{10}$ to minimize the surface energy prior to infusing the lubricant. Gold coating on VG was performed to achieve a strong chemical bond with thiol. Then, the samples were dipped in the lubricant (Krytox 1525, Sigma-Aldrich, dynamic viscosity $496 \mathrm{mPa}$, surface tension $19 \mathrm{mN} \mathrm{m}^{-1}$, density $1900 \mathrm{~kg} \mathrm{~m}^{-3}$ ) for $15 \mathrm{~min}$. After that, the samples were kept vertically oriented for 1 day followed by a $\mathrm{N}_{2}$ purge to remove the excess lubricant. Krytox 1525 has a low surface tension, a low vapor pressure, and a high kinematic viscosity as compared to other commonly used lubricants. Due to low surface tension, it can be also used for the condensation of low surface tension liquids and refrigerants. ${ }^{25}$ As the vapor pressure is low, it will not evaporate easily, and hence, the durability of the lubricant infused surface will be better. Krytox 1525 has also a relatively higher viscosity, which delays the cloaking event, ${ }^{63}$ and hence, less lubricant is expected to get depleted during the condensation experiment. We determined the wettability of all the fabricated substrates by performing water contact angle and contact angle hysteresis measurement using a goniometer (OCA 35, DataPhysics). The contact angle and contact angle hysteresis values reported for all the fabricated surfaces include standard deviation and measurement uncertainties ${ }^{67}( \pm$ value $=$ $\sqrt{\text { uncertainty }^{2}+\text { stdev }^{2}}$ ).

Fabrication of CuO Nanostructured Superhydrophilic Surface and CuO Lubricant-Infused Surface. The copper substrate was first cleaned in an ultrasonic bath with acetone, IPA, and DI water followed by drying in a $\mathrm{N}_{2}$ blow. Then, the substrate was dipped in to 2 $\mathrm{M}$ hydrochloric acid ( $\mathrm{HCl}$ ) for 50-60 s to remove the oxide layer. The substrate was again rinsed with DI water and dried with $\mathrm{N}_{2}$. To fabricate the $\mathrm{CuO}$ nanostructured surface, the cleaned copper substrate was dipped in a hot alkali solution (a mixture of $\mathrm{NaClO}_{2}, \mathrm{NaOH}$, and $\mathrm{Na}_{3} \mathrm{PO}_{4} / 12 \mathrm{H}_{2} \mathrm{O}$ ) for $4-5 \mathrm{~min} .{ }^{68}$ The temperature of the alkali solution was maintained at $95{ }^{\circ} \mathrm{C}$. The copper samples turned black after the reaction due to the formation of $\mathrm{CuO}$ nanoblades. The morphology of the surface was observed using SEM (SU8230, Hitachi), as shown in Figure S5. The height of the $\mathrm{CuO}$ nanostructures formed was $h \approx 2 \mu \mathrm{m}$ with a thermal conductivity of $20-33 \mathrm{~W} \mathrm{~m}^{-1} \mathrm{~K}^{-1}$. 25,64,69 To fabricate the $\mathrm{CuO}$ lubricant-infused surfaces, samples were first dipped in an ethanolic thiol (perfluordecanthiol (PFDT), Sigma-Aldrich) solution followed by dipping in Krytox 1525 for $15 \mathrm{~min}$, and then, the samples were kept vertically for $24 \mathrm{~h}$ to drain the excess lubricant.

Heat Transfer Measurement and Durability Experiment. See Sections S1 and S2 for details.

\section{ASSOCIATED CONTENT}

\section{Supporting Information}

The Supporting Information is available free of charge at https://pubs.acs.org/doi/10.1021/acsnano.1c02932.

Schematic of Bernal stacking and the arrangement of carbon atoms in graphene sheets, SEM images, water droplet images, schematic of the experimental setup for the spinning test, schematic of the lubricant depletion test, Beeswarm plot for the distribution of departure diameters, schematic and description of the overall condensation setup, schematic and description of the condensation chamber, chamber leakage tests, heat flux and chamber steam flow speed at different subcooling values, flow conditions during the durability test, location of temperature sensors, thermal resistance estimation, parallel thermal resistance circuit, nanostructure height profile extraction, heat transfer measurements and snapshots of condensation behavior for additional superhydrophobic and graphene surfaces, tables of comparison of VG LIS with the current state-of-the-art collection of LIS, properties of VG, wettability of VG LIS after water droplet sliding test, steam flow and condensation conditions, sample mounting, computation of heat transfer coefficients and error propagation, measurement procedures of droplet departure diameters, HTC without taking thermal resistance into account (PDF)

Video of condensation behavior on the as-fabricated $\mathrm{CuO}$ nanostructured superhydrophilic surface, $\mathrm{CuO}$ LIS, and VG LIS (MP4)

Video of durability experiment of VG LIS (MP4)

\section{AUTHOR INFORMATION}

\section{Corresponding Author}

Dimos Poulikakos - Laboratory of Thermodynamics in Emerging Technologies, Department of Mechanical and Process Engineering, ETH Zurich, 8092 Zurich, Switzerland; (1) orcid.org/0000-0001-5733-6478; Phone: +41 4463227 38; Email: dpoulikakos@ethz.ch; Fax: +41 446321176 


\section{Authors}

Abinash Tripathy - Laboratory of Thermodynamics in Emerging Technologies, Department of Mechanical and Process Engineering, ETH Zurich, 8092 Zurich, Switzerland; (1) orcid.org/0000-0003-3546-2806

Cheuk Wing Edmond Lam - Laboratory of Thermodynamics in Emerging Technologies, Department of Mechanical and Process Engineering, ETH Zurich, 8092 Zurich, Switzerland; (1) orcid.org/0000-0002-8782-8438

Diana Davila - IBM Research, 8803 Rueschlikon, Switzerland

Matteo Donati - Laboratory of Thermodynamics in Emerging Technologies, Department of Mechanical and Process Engineering, ETH Zurich, 8092 Zurich, Switzerland; (1) orcid.org/0000-0003-0197-0159

Athanasios Milionis - Laboratory of Thermodynamics in Emerging Technologies, Department of Mechanical and Process Engineering, ETH Zurich, 8092 Zurich, Switzerland; (1) orcid.org/0000-0002-0049-1255

Chander Shekhar Sharma - Thermofluidics Research Lab, Department of Mechanical Engineering, Indian Institute of Technology Ropar, Rupnagar, Punjab 140001, India; ○ orcid.org/0000-0002-6193-6457

Complete contact information is available at: https://pubs.acs.org/10.1021/acsnano.1c02932

\section{Author Contributions}

"A.T. and C.W.E.L. contributed equally to this work. A.T. and D.P. conceived the research. A.M., C.S.S., and D.P. provided scientific guidance in all of its aspects. A.T. and D.D.P. fabricated and characterized the samples. A.T. performed the lubricant depletion tests by spinning method and droplet sliding. C.W.E.L. designed and constructed the condensation chamber; and performed all the experiments and data analyses related to condensation and heat transfer. M.D. applied the gold coating on vertical graphene. The manuscript was written with the contribution of all the authors.

\section{Funding}

This project has received funding from the European Union's Horizon 2020 research and innovation program under grant number 801229 (HARMoNIC).

\section{Notes}

All the data used in the main manuscript and the Supporting Information to support the claims are available from the corresponding author upon reasonable request.

The authors declare no competing financial interest.

\section{ACKNOWLEDGMENTS}

The authors would like to thank Mr. Jovo Vidic for his help in the setup of the data acquisition system and Mr. Peter Feusi for his help in the construction of the condensation chamber for the heat transfer experiments. The authors would like to thank the Cleanroom Operations Team of the Binnig and Rohrer Nanotechnology Center (BRNC) for their help and support.

\section{REFERENCES}

(1) Enright, R.; Miljkovic, N.; Alvarado, J. L.; Kim, K.; Rose, J. W. Dropwise Condensation on Micro-and Nanostructured Surfaces. Nanoscale Microscale Thermophys. Eng. 2014, 18, 223-250.

(2) Attinger, D.; Frankiewicz, C.; Betz, A. R.; Schutzius, T. M.; Ganguly, R.; Das, A.; Kim, C.-J.; Megaridis, C. M. Surface Engineering for Phase Change Heat Transfer: A Review. MRS Energy Sustain. 2014, $1,1-40$.
(3) Cho, H. J.; Preston, D. J.; Zhu, Y.; Wang, E. N. Nanoengineered Materials for Liquid-Vapour Phase-Change Heat Transfer. Nat. Rev. Mater. 2017, 2, 1-17.

(4) Edalatpour, M.; Liu, L.; Jacobi, A. M.; Eid, K. F.; Sommers, A. D. Managing Water on Heat Transfer Surfaces: A Critical Review of Techniques to Modify Surface Wettability for Applications with Condensation or Evaporation. Appl. Energy 2018, 222, 967-992.

(5) Paxson, A. T.; Yagüe, J. L.; Gleason, K. K.; Varanasi, K. K. Stable Dropwise Condensation for Enhancing Heat Transfer via the Initiated Chemical Vapor Deposition (ICVD) of Grafted Polymer Films. Adv. Mater. 2014, 26, 418-423.

(6) Rykaczewski, K.; Paxson, A. T.; Anand, S.; Chen, X.; Wang, Z.; Varanasi, K. K. Multimode Multidrop Serial Coalescence Effects during Condensation on Hierarchical Superhydrophobic Surfaces. Langmuir 2013, 29, 881-891.

(7) Mulroe, M. D.; Srijanto, B. R.; Ahmadi, S. F.; Collier, C. P.; Boreyko, J. B. Tuning Superhydrophobic Nanostructures to Enhance Jumping-Droplet Condensation. ACS Nano 2017, 11, 8499-8510.

(8) Schmidt, E.; Schurig, W.; Sellschopp, W. Versuche Über Die Kondensation von Wasserdampf in Film- Und Tropfenform. Forsch. Ingenieurwes. 1930, 1, 53-63.

(9) Rose, J. W. Dropwise Condensation Theory and Experiment: A Review. Proc. Inst. Mech. Eng., Part A 2002, 216, 115-128.

(10) Sharma, C. S.; Stamatopoulos, C.; Suter, R.; Von Rohr, P. R.; Poulikakos, D. Rationally 3D-Textured Copper Surfaces for Laplace Pressure Imbalance-Induced Enhancement in Dropwise Condensation. ACS Appl. Mater. Interfaces 2018, 10, 29127-29135.

(11) Sharma, C. S.; Combe, J.; Giger, M.; Emmerich, T.; Poulikakos, D. Growth Rates and Spontaneous Navigation of Condensate Droplets through Randomly Structured Textures. ACS Nano 2017, 11, 16731682 .

(12) Donati, M.; Lam, C. W. E.; Milionis, A.; Sharma, C. S.; Tripathy, A.; Zendeli, A.; Poulikakos, D. Sprayable Thin and Robust Carbon Nanofiber Composite Coating for Extreme Jumping Dropwise Condensation Performance. Adv. Mater. Interfaces 2021, 8, 2001176.

(13) Liu, Y.; Choi, C. H. Condensation-Induced Wetting State and Contact Angle Hysteresis on Superhydrophobic Lotus Leaves. Colloid Polym. Sci. 2013, 291, 437-445.

(14) Jo, H.; Hwang, K. W.; Kim, D.; Kiyofumi, M.; Park, H. S.; Kim, M. H.; Ahn, H. S. Loss of Superhydrophobicity of Hydrophobic Micro/ Nano Structures during Condensation. Sci. Rep. 2015, 5, 5-10.

(15) Dai, X.; Sun, N.; Nielsen, S. O.; Stogin, B. B.; Wang, J.; Yang, S.; Wong, T. S. Hydrophilic Directional Slippery Rough Surfaces for Water Harvesting. Sci. Adv. 2018, 4, 1-11.

(16) Tsuchiya, H.; Tenjimbayashi, M.; Moriya, T.; Yoshikawa, R.; Sasaki, K.; Togasawa, R.; Yamazaki, T.; Manabe, K.; Shiratori, S. LiquidInfused Smooth Surface for Improved Condensation Heat Transfer. Langmuir 2017, 33, 8950-8960.

(17) Miljkovic, N.; Enright, R.; Wang, E. N. Effect of Droplet Morphology on Growth Dynamics and Heat Transfer during Condensation on Superhydrophobic Nanostructured Surfaces. ACS Nano 2012, 6, 1776-1785.

(18) Chen, X.; Wu, J.; Ma, R.; Hua, M.; Koratkar, N.; Yao, S.; Wang, Z. Nanograssed Micropyramidal Architectures for Continuous Dropwise Condensation. Adv. Funct. Mater. 2011, 21, 4617-4623.

(19) Wilke, K. L.; Preston, D. J.; Lu, Z.; Wang, E. N. Toward Condensation-Resistant Omniphobic Surfaces. ACS Nano 2018, 12, 11013-11021.

(20) Wen, R.; Xu, S.; Ma, X.; Lee, Y. C.; Yang, R. Three-Dimensional Superhydrophobic Nanowire Networks for Enhancing Condensation Heat Transfer. Joule 2018, 2, 269-279.

(21) Olceroglu, E.; McCarthy, M. Self-Organization of Microscale Condensate for Delayed Flooding of Nanostructured Superhydrophobic Surfaces. ACS Appl. Mater. Interfaces 2016, 8, 5729-5736.

(22) Khalil, K.; Soto, D.; Farnham, T.; Paxson, A.; Katmis, A. U.; Gleason, K.; Varanasi, K. K. Grafted Nanofilms Promote Dropwise Condensation of Low-Surface-Tension Fluids for High-Performance Heat Exchangers. Joule 2019, 3, 1377-1388. 
(23) Baumli, P.; D’Acunzi, M.; Hegner, K. I.; Naga, A.; Wong, W. S. Y.; Butt, H. J.; Vollmer, D. The Challenge of Lubricant-Replenishment on Lubricant-Impregnated Surfaces. Adv. Colloid Interface Sci. 2021, 287, 102329.

(24) Xiao, R.; Miljkovic, N.; Enright, R.; Wang, E. N. Immersion Condensation on Oil-Infused Heterogeneous Surfaces for Enhanced Heat Transfer. Sci. Rep. 2013, 3, 1988.

(25) Sett, S.; Sokalski, P.; Boyina, K.; Li, L.; Rabbi, K. F.; Auby, H.; Foulkes, T.; Mahvi, A.; Barac, G.; Bolton, L. W.; Miljkovic, N. Stable Dropwise Condensation of Ethanol and Hexane on Rationally Designed Ultrascalable Nanostructured Lubricant-Infused Surfaces. Nano Lett. 2019, 19, 5287-5296.

(26) Sun, J.; Weisensee, P. B. Microdroplet Self-Propulsion during Dropwise Condensation on Lubricant-Infused Surfaces. Soft Matter 2019, 15, 4808-4817.

(27) Anand, S.; Paxson, A. T.; Dhiman, R.; Smith, J. D.; Varanasi, K. K. Enhanced Condensation on Lubricant-Impregnated Nanotextured Surfaces. ACS Nano 2012, 6, 10122-10129.

(28) Adera, S.; Alvarenga, J.; Shneidman, A. V.; Zhang, C. T.; Davitt, A.; Aizenberg, J. Depletion of Lubricant from Nanostructured OilInfused Surfaces by Pendant Condensate Droplets. ACS Nano 2020, 14, 8024-8035.

(29) Wong, T. S.; Kang, S. H.; Tang, S. K. Y.; Smythe, E. J.; Hatton, B. D.; Grinthal, A.; Aizenberg, J. Bioinspired Self-Repairing Slippery Surfaces with Pressure-Stable Omniphobicity. Nature 2011, 477, 443447.

(30) Epstein, A. K.; Wong, T. S.; Belisle, R. A.; Boggs, E. M.; Aizenberg, J. Liquid-Infused Structured Surfaces with Exceptional AntiBiofouling Performance. Proc. Natl. Acad. Sci. U. S. A. 2012, 109, 13182-13187.

(31) Kim, P.; Wong, T. S.; Alvarenga, J.; Kreder, M. J.; AdornoMartinez, W. E.; Aizenberg, J. Liquid-Infused Nanostructured Surfaces with Extreme Anti-Ice and Anti-Frost Performance. ACS Nano 2012, 6, 6569-6577.

(32) Glavan, A. C.; Martinez, R. V.; Subramaniam, A. B.; Yoon, H. J.; Nunes, R. M. D.; Lange, H.; Thuo, M. M.; Whitesides, G. M. Omniphobic "RF Paper" Produced by Silanization of Paper with Fluoroalkyltrichlorosilanes. Adv. Funct. Mater. 2014, 24, 60-70.

(33) Guo, J.; Fang, W.; Welle, A.; Feng, W.; Filpponen, I.; Rojas, O. J.; Levkin, P. A. Superhydrophobic and Slippery Lubricant-Infused Flexible Transparent Nanocellulose Films by Photoinduced ThiolEne Functionalization. ACS Appl. Mater. Interfaces 2016, 8, 3411534122 .

(34) Tesler, A. B.; Kim, P.; Kolle, S.; Howell, C.; Ahanotu, O.; Aizenberg, J. Extremely Durable Biofouling-Resistant Metallic Surfaces Based on Electrodeposited Nanoporous Tungstite Films on Steel. Nat. Commun. 2015, 6, 8649.

(35) Juuti, P.; Haapanen, J.; Stenroos, C.; Niemelä-Anttonen, H.; Harra, J.; Koivuluoto, H.; Teisala, H.; Lahti, J.; Tuominen, M.; Kuusipalo, J.; Vuoristo, P.; Mäkelä, J. M. Achieving a Slippery, LiquidInfused Porous Surface with Anti-Icing Properties by Direct Deposition of Flame Synthesized Aerosol Nanoparticles on a Thermally Fragile Substrate. Appl. Phys. Lett. 2017, 110, 161603.

(36) Howell, C.; Vu, T. L.; Lin, J. J.; Kolle, S.; Juthani, N.; Watson, E.; Weaver, J. C.; Alvarenga, J.; Aizenberg, J. Self-Replenishing Vascularized Fouling-Release Surfaces. ACS Appl. Mater. Interfaces 2014, 6, 13299-13307.

(37) Damle, V. G.; Uppal, A.; Sun, X.; Burgin, T. P.; Rykaczewski, K. Rapid and Scalable Lubrication and Replenishment of Liquidinfused Materials. Surf. Innovations 2016, 4, 102-108.

(38) Cui, J.; Daniel, D.; Grinthal, A.; Lin, K.; Aizenberg, J. Dynamic Polymer Systems with Self-Regulated Secretion for the Control of Surface Properties and Material Healing. Nat. Mater. 2015, 14, 790795.

(39) Tenjimbayashi, M.; Nishioka, S.; Kobayashi, Y.; Kawase, K.; Li, J.; Abe, J.; Shiratori, S. A Lubricant-Sandwiched Coating with LongTerm Stable Anticorrosion Performance. Langmuir 2018, 34, 13861393.
(40) Pop, E.; Varshney, V.; Roy, A. K. Thermal Properties of Graphene: Fundamentals and Applications. MRS Bull. 2012, 37, 12731281.

(41) Raj, R.; Maroo, S. C.; Wang, E. N. Wettability of Graphene. Nano Lett. 2013, 13, 1509-1515.

(42) Hong, G.; Han, Y.; Schutzius, T. M.; Wang, Y.; Pan, Y.; Hu, M.; Jie, J.; Sharma, C. S.; Müller, U.; Poulikakos, D. On the Mechanism of Hydrophilicity of Graphene. Nano Lett. 2016, 16, 4447-4453.

(43) Shin, Y. J.; Wang, Y.; Huang, H.; Kalon, G.; Wee, A. T. S.; Shen, Z.; Bhatia, C. S.; Yang, H. Surface-Energy Engineering of Graphene. Langmuir 2010, 26, 3798-3802.

(44) Zang, J.; Ryu, S.; Pugno, N.; Wang, Q.; Tu, Q.; Buehler, M. J.; Zhao, X. Multifunctionality and Control of the Crumpling and Unfolding of Large-Area Graphene. Nat. Mater. 2013, 12, 321-325.

(45) Ci, H.; Ren, H.; Qi, Y.; Chen, X.; Chen, Z.; Zhang, J.; Zhang, Y.; Liu, Z. 6-Inch Uniform Vertically-Oriented Graphene on Soda-Lime Glass for Photothermal Applications. Nano Res. 2018, 11, 3106-3115.

(46) Preston, D. J.; Mafra, D. L.; Miljkovic, N.; Kong, J.; Wang, E. N. Scalable Graphene Coatings for Enhanced Condensation Heat Transfer. Nano Lett. 2015, 15, 2902-2909.

(47) Chen, J.; Bo, Z.; Lu, G. Vertically-Oriented Graphene; Springer. 2015.

(48) Cai, M.; Outlaw, R. A.; Quinlan, R. A.; Premathilake, D.; Butler, S. M.; Miller, J. R. Fast Response, Vertically Oriented Graphene Nanosheet Electric Double Layer Capacitors Synthesized from $\mathrm{C}_{2} \mathrm{H}_{2}$. ACS Nano 2014, 8, 5873-5882.

(49) Bo, Z.; Mao, S.; Jun Han, Z.; Cen, K.; Chen, J.; Ostrikov, K. Emerging Energy and Environmental Applications of VerticallyOriented Graphenes. Chem. Soc. Rev. 2015, 44, 2108-2121.

(50) Shuai, X.; Bo, Z.; Kong, J.; Yan, J.; Cen, K. Wettability of Vertically-Oriented Graphenes with Different Intersheet Distances. RSC Adv. 2017, 7, 2667-2675.

(51) Rafiee, J.; Mi, X.; Gullapalli, H.; Thomas, A. V.; Yavari, F.; Shi, Y.; Ajayan, P. M.; Koratkar, N. A. Wetting Transparency of Graphene. Nat. Mater. 2012, 11, 217-222.

(52) Mishra, K. K.; Ghosh, S.; Ravindran, T. R.; Amirthapandian, S.; Kamruddin, M. Thermal Conductivity and Pressure-Dependent Raman Studies of Vertical Graphene Nanosheets. J. Phys. Chem. C 2016, 120, 25092-25100.

(53) Preston, D. J.; Lu, Z.; Song, Y.; Zhao, Y.; Wilke, K. L.; Antao, D. S.; Louis, M.; Wang, E. N. Heat Transfer Enhancement during Water and Hydrocarbon Condensation on Lubricant Infused Surfaces. Sci. Rep. 2018, 8, 1-9.

(54) Ferrari, A. C.; Basko, D. M. Raman Spectroscopy as a Versatile Tool for Studying the Properties of Graphene. Nat. Nanotechnol. 2013, $8,235-246$.

(55) Heller, E. J.; Yang, Y.; Kocia, L.; Chen, W.; Fang, S.; Borunda, M.; Kaxiras, E. Theory of Graphene Raman Scattering. ACS Nano 2016, 10, 2803-2818.

(56) Ghosh, S.; Ganesan, K.; Polaki, S. R.; Ravindran, T. R.; Krishna, N. G.; Kamruddin, M.; Tyagi, A. K. Evolution and Defect Analysis of Vertical Graphene Nanosheets. J. Raman Spectrosc. 2014, 45, 642-649.

(57) Malard, L. M.; Pimenta, M. A.; Dresselhaus, G.; Dresselhaus, M. S. Raman Spectroscopy in Graphene. Phys. Rep. 2009, 473, 51-87.

(58) Ferrante, C.; Virga, A.; Benfatto, L.; Martinati, M.; De Fazio, D.; Sassi, U.; Fasolato, C.; Ott, A. K.; Postorino, P.; Yoon, D.; Cerullo, G.; Mauri, F.; Ferrari, A. C.; Scopigno, T. Raman Spectroscopy of Graphene under Ultrafast Laser Excitation. Nat. Commun. 2018, 9, 18.

(59) Baranov, O.; Levchenko, I.; Xu, S.; Lim, J. W. M.; Cvelbar, U.; Bazaka, K. Formation of Vertically Oriented Graphenes: What Are the Key Drivers of Growth? 2D Mater. 2018, 5, 044002.

(60) Tzouvadaki, I.; Aliakbarinodehi, N.; Dávila Pineda, D.; De Micheli, G.; Carrara, S. Graphene Nanowalls for High-Performance Chemotherapeutic Drug Sensing and Anti-Fouling Properties. Sens. Actuators, B 2018, 262, 395-403.

(61) DuPont Krytox.USA 2012, 5, 8-9.

(62) Kim, P.; Kreder, M. J.; Alvarenga, J.; Aizenberg, J. Hierarchical or Not? Effect of the Length Scale and Hierarchy of the Surface Roughness 
on Omniphobicity of Lubricant-Infused Substrates. Nano Lett. 2013, 13, 1793-1799.

(63) Carlson, A.; Kim, P.; Amberg, G.; Stone, H. A. Short and Long Time Drop Dynamics on Lubricated Substrates. Epl. 2013, 104, 34008.

(64) Liu, M. S.; Lin, M. C. C.; Wang, C. C. Enhancements of Thermal Conductivities with $\mathrm{Cu}, \mathrm{CuO}$, and Carbon Nanotube Nanofluids and Application of MWNT/Water Nanofluid on a Water Chiller System. Nanoscale Res. Lett. 2011, 6, 297.

(65) Cho, J. H.; Gorman, J. J.; Na, S. R.; Cullinan, M. Growth of Monolayer Graphene on Nanoscale Copper-Nickel Alloy Thin Films. Carbon 2017, 115, 441-448.

(66) Zhu, M.; Wang, J.; Holloway, B. C.; Outlaw, R. A.; Zhao, X.; Hou, K.; Shutthanandan, V.; Manos, D. M. A Mechanism for Carbon Nanosheet Formation. Carbon 2007, 45, 2229-2234.

(67) Liu, K.; Vuckovac, M.; Latikka, M.; Huhtamäki, T.; Ras, R. H. A. Improving Surface-Wetting Characterization. Science 2019, 363, 11471148.

(68) Enright, R.; Miljkovic, N.; Dou, N.; Nam, Y.; Wang, E. N. Condensation on Superhydrophobic Copper Oxide Nanostructures. J. Heat Transfer 2013, 135, 091304.

(69) Kwak, K.; Kim, C. Viscosity and Thermal Conductivity of Copper Oxide Nanofluid Dispersed in Ethylene Glycol. Korea-australia Rheol. J. 2005, 17, 35-40. 